REVISTA DEESTUDIOS BRASILEÑOS

e-ISSN: $2386-4540$

https://doi.org/10.14201/

reb20196121325

AUTOR

Javier Sánchez

Bernal*

jsbernal@usal.es

* Profesor ayudante doctor del Departamento de Derecho Público Genera de la USAL.

\section{Los delitos de corrupción en el deporte en España, Portugal y Brasil. Similitudes y diferencias}

\author{
Os crimes de corrupção no esporte na Espanha, Portugal e Brasil. \\ Semelhanças e diferenças \\ Crimes of corruption in sports in Spain, Portugal and Brazil. \\ Similarities and differences
}

\section{RESUMEN:}

En las últimas décadas, fruto de la globalización, se ha superado la perspectiva de que los fenómenos de corrupción constituyen un problema local que afecta únicamente al sector público interno de los distintos Estados y es considerado, cada vez más, un problema transfronterizo. Esto ha intensificado el interés de distintas instancias supranacionales en la prevención y represión de los mismos. La evolución de las sociedades actuales ha evidenciado que los ilícitos de soborno pueden asentarse no sólo en el ámbito público, sino también en el privado $\mathrm{y}$, concretamente, en la esfera deportiva, donde se ponen en juego un mayor número de intereses de relevancia económica. Este trabajo trata de comparar las soluciones aportadas por los ordenamientos jurídico-penales de España, Portugal y Brasil en la represión de comportamientos de corrupción en el deporte.

\section{RESUMO:}

Nas últimas décadas, como resultado da globalização, foi superada a perspectiva de que os fenômenos de corrupção constituem um problema local, que afeta apenas o setor público interno dos diferentes Estados, e, cada vez mais, passa a ser considerado um problema transfronteiriço. Isso intensificou o interesse de diferentes instâncias supranacionais na sua prevenção e repressão. A evolução das sociedades atuais mostrou que o suborno ilegal pode ser estabelecido não apenas na esfera pública, mas também no setor privado e, especificamente, na esfera esportiva, onde está em jogo um maior número de interesses economicamente relevantes. Este trabalho tenta comparar as soluções dadas pelos sistemas penal-legais da Espanha, Portugal e Brasil na repressão ao comportamento corrupto no esporte.

\section{ABSTRACT:}

In recent decades, as a result of globalization, the prospect that the phenomena of corruption are only a local problem has been exceeded, affecting the public sector of individual states, and it's been considered, increasingly, a transboundary problem. This has intensified the interest of various supranational bodies in the prevention and suppression of them. The evolution of current societies has shown that illegal bribery can settle not only in the public sphere, but also in the private and specifically in the sports field, where more economically relevant interests are at stake. This paper attempts to compare the solutions provided by the criminal rules in Spain, Portugal and Brazil in repression of corrupt behavior in sports. 


\section{Introducción}

La corrupción ha dejado de ser un problema local para convertirse en un fenómeno transnacional que afecta a todas las sociedades y economías (Naciones Unidas, 2003, p. 5), con independencia del sistema político o del nivel de renta de los individuos. La proliferación de los efectos negativos que estas conductas generan en todos los ámbitos, y su gravedad, justifica la creciente atención de diversos actores públicos y privados (Flórez, 2008, p. 7) en la prevención, enjuiciamiento y sanción de los comportamientos corruptos, hasta el punto de que, en la actualidad, se ha instaurado una política criminal de tolerancia cero contra la corrupción. En este sentido, se ha sostenido con acierto que, desde el punto de vista jurídico-penal, la corrupción es uno de los problemas más característicos de la comunidad globalizada (Nieto Martín, 2002, p. 55).

Así, en este contexto, el ámbito de lo penalmente relevante, en lo que al fenómeno de la corrupción se refiere, está sufriendo, en los últimos años, un innegable proceso de expansión. Ello se verifica tanto en el marco de los comportamientos delictivos producidos en el sector público, como a través de la incorporación de figuras destinadas a penar los abusos de poder en el sector privado (Caruso Fontán, 2009, p. 146) y, particularmente, en la esfera empresarial y comercial, y en la deportiva.

Este trabajo se focalizará en la tipificación penal de la corrupción en el deporte, tratando de acercarse y dar unas pinceladas con respecto al modo en que los ordenamientos penales de España, Portugal y Brasil regulan esta nueva clase de corrupción, la que se produce en el ámbito de los eventos deportivos, centrando su atención en el bien jurídico que subyace en la redacción típica de cada uno de estos países. No obstante, considero imprescindible previamente aportar algunas ideas acerca del por qué el Derecho penal ha comenzado a intervenir en el "hecho deportivo".

\subsection{Trascendencia social del deporte}

La preocupación por los fenómenos de fraude en las competiciones deportivas es evidentemente reciente. Uno de los factores que explica la intervención penal en el deporte es, sin duda, el peso, cada vez más relevante, del mismo en la vida social. El mundo del deporte ha alcanzado unas dimensiones sociológicas, económicas, culturales y educativas que irradian valores y modelos de comportamiento que traspasan todo tipo de límites y fronteras territoriales, sociales y económicas. Además, la incorporación de internet al mundo de las apuestas deportivas ha multiplicado exponencialmente tanto los sujetos, como los intereses directamente derivados de un determinado resultado, como las modalidades de conducta en el ámbito de la práctica deportiva (Benítez Ortúzar, 2011, pp. 15-16).

El deporte cumple una importante función social ${ }^{1}$ que lo hace trascender de una mera práctica saludable; es, sin duda, parte de la vida de las personas, erigiéndose así en un componente social de primera magnitud (García Caba, 2009b, p. 77). Esta relevancia se hace evidente y se intensifica en el deporte profesional, lo que conlleva una innegable y correlativa repercusión económica. Por tal sentido, uno de los caracteres asociados a este deporte profesional viene dado por "las propias cifras astronómicas de dinero" que se mueven dentro y de forma ajena al mismo, con la proliferación de las apuestas deportivas. De este modo, desde una perspectiva meramente económica, son destacables "las elevadas cuantías en las que puede[n] materializarse [los fraudes deportivos], con un elenco de perjudicados innumerable, ad intra y ad extra de los propios deportistas, entidades y organizaciones deportivas" (Benítez Ortúzar, 2011, pp. 38-40). 
De este modo, como se apunta, la creciente importancia social, política y económica del "hecho deportivo" ha dado lugar a una reacción institucional de los poderes públicos, tanto desde una óptica normativa como orgánica. La intervención pública en el deporte, en palabras del Tribunal Supremo español, "trata de amparar una actividad de indudable utilidad pública, y que forma parte del conjunto de elementos que tienden no sólo ya a proporcionar medios materiales a los ciudadanos, sino a mejorar la calidad de su vida cotidiana"2. Hasta tal punto es así que algún autor ha reconocido que la Administración Pública, pero no una cualquiera, sino la Administración deportiva especializada, "debe desempeñar un rol fundamental para erigirse como uno de los principales guardianes de los valores de lealtad y corrección en el deporte, convirtiéndose así en uno de los principales sujetos que luchen para erradicar conductas fraudulentas en el deporte" (García Caba, 2009, p. 79).

Volvamos entonces al binomio deporte y dinero. El Informe de Helsinki sobre el deporte, citado en una nota al pie anterior, alerta de esta relación perversa entre efectos económicos y función social del deporte. Reconoce que la multiplicación de los espectáculos deportivos lucrativos puede conducir a que la lógica comercial prime sobre la deportiva y la función social de este. La evolución que se ha mencionado tiene unas consecuencias claras: el desbordamiento de los efectos de determinados deportes al mundo económico es evidente; la proliferación de casas de apuestas por internet - entre otras circunstancias, como la trasnacionalidad de las competiciones y de las hipotéticas actuaciones ilícitas, añadiría yo - dan lugar a complejas organizaciones criminales que sobrepasan cualquier figura delictiva tradicional (Benítez Ortúzar, 2011, p. 40).

Así las cosas, una vez explorado el porqué de la actuación de los poderes públicos en el deporte, vislumbramos un paso más: la intervención del Derecho penal. Antes de analizar más en profundidad esta cuestión, sin embargo, conviene precisar qué vamos a entender, desde el punto de vista jurídico, por corrupción en el deporte.

\section{Conceptualización de la corrupción en el deporte y justificación de la intervención penal}

Efectivamente, apoyando el argumento de Benítez Ortúzar, "antes de sistematizar las conductas constitutivas de fraude deportivo parece sensato definir lo que, jurídicamente, debe considerarse” tal (Benítez Ortúzar, 2011, p. 52). Como primera aproximación, conviene citar a Eser, quien se refiere a esta clase de corrupción, sin citarla, como aquellos "delitos cuya finalidad es la manipulación ilícita de los resultados de las pruebas deportivas” (Eser, 1990, p. 1132). Benítez Ortúzar, partiendo de este acercamiento, reconoce que estas figuras - refiriéndose a las conductas de fraude en el deporte - "van a venir marcadas por una finalidad concreta, consistente en alterar maliciosamente una realidad", siendo conductas que "giran en torno al engaño" (Benítez Ortúzar, 2011, p. 53). Para el citado autor, haciendo una lectura global de su argumentación, la corrupción en el deporte implicaría algo así como la alteración de un resultado de un encuentro o competición deportiva, de modo engañoso, falaz, mendaz, y presuponiendo una vulneración de las reglas de la competición (Benítez Ortúzar, 2011, pp. 56-58).

Una vez delimitado, siquiera sintéticamente, el concepto de corrupción o fraude deportivo - expresiones que en este trabajo se utilizarán de modo sinónimo -, conviene preguntarse, como se apuntó anteriormente, por qué o cómo se justifica la intervención del Derecho penal para la represión de este tipo de comportamientos.

La primera cuestión que debe resaltarse es que, en contra de lo que sucede con otros fenómenos de corrupción, como la corrupción entre particulares, la tipificación del fraude en el deporte - al menos, en el contexto europeo, que tomamos como referencia - no viene inducida por el cumplimiento de obligaciones comunitarias o supranacionales, sino que "surge de forma espontánea y por impulso exclusivo de nuestros legisladores" (Cortés Bechiarelli, 2012, p. 21). 
Siendo así, resulta interesante tratar de averiguar lo que llevó al legislador penal a introducir esta figura en el ordenamiento. Para Benítez Ortúzar, el Derecho penal entra a conocer de estas conductas debido a los escasos recursos probatorios con los que cuentan los órganos disciplinarios deportivos. De este modo, el orden penal permitiría una mayor eficacia en la lucha contra este tipo de actuaciones (Benítez Ortúzar, 2011, pp. 59-60). La reflexión de Cortés Bechiarelli camina en el mismo sentido. Para este autor, la disciplina deportiva disponía ya de medios proporcionales para reprimir esta clase de sobornos, si bien es cierto que la investigación de estos amaños no podía apoyarse en la limitación de derechos fundamentales y libertades públicas. Sin embargo, concluye, "la conversión de estas infracciones deportivas (...) en delitos para con ello ser probadas con mayor facilidad no es un argumento que valide la incriminación de la conducta ni, menos, una razón político-criminalmente asumible" (Cortés Bechiarelli, 2012, pp. 66-67).

Así las cosas, vemos que, cuanto menos en el Derecho penal español, la represión de estos comportamientos viene dada por la ineficacia del Derecho administrativo disciplinario a la hora de prevenir y sancionar esta clase de fraude. Por su parte, en el Derecho penal portugués - otro de los ordenamientos analizados en este trabajo -, la introducción de este delito mediante la Lei $n^{\circ} 50 / 2007$, de 31 de agosto - ley penal especial propia -, se debió, fundamentalmente, a la extraordinaria relevancia del escándalo de 'Silbato Dorado', que saltó a la luz en 2004 y en el que fueron detenidos árbitros, representantes y el presidente de la Liga de Fútbol Profesional, acusados de varios delitos, entre ellos corrupción y manipulación arbitral (García Caba, 2009 , p. 322). Ello condujo al legislador portugués a la elaboración de esta ley penal especial propia, cuyo objetivo es establecer un régimen penal por comportamientos antideportivos (Morillas Cueva, 2009, p. 69).

\section{El delito de corrupción deportiva en España}

El tipo de corrupción deportiva es relativamente reciente en el Código penal español. Fue introducido por la Ley Orgánica 5/2010, de 22 de junio y reformado de modo importante - a pesar de que no se había aplicado nunca - a través de la Ley Orgánica 1/2015, de 30 de marzo. La figura básica se tipifica en el apartado $4^{\circ}$ del artículo 286 bis del Código, recogiendo el apartado $3^{\circ}$ del mismo precepto la modalidad atenuada y, desde la entrada en vigor de la Ley Orgánica de 2015, previéndose, además, varias conductas agravadas en el artículo 286 quater.

\subsection{La redacción dada por la L.0. 5/2010}

Artículo 286 bis (tipo básico)

4. Lo dispuesto en este artículo será aplicable, en sus respectivos casos, a los directivos, administradores, empleados o colaboradores de una entidad deportiva, cualquiera que sea la forma jurídica de ésta, así como a los deportistas, árbitros o jueces, respecto de aquellas conductas que tengan por finalidad predeterminar o alterar de manera deliberada y fraudulenta el resultado de una prueba, encuentro o competición deportiva profesionales.

Artículo 286 bis (modalidad atenuada).

3. Los jueces y tribunales, en atención a la cuantía del beneficio o al valor de la ventaja, y a la trascendencia de las funciones del culpable, podrán imponer la pena inferior en grado y reducir la de multa a su prudente arbitrio.

Comencemos por revisar, entonces, la redacción original, fruto de la L.O. 5/2010. Se ha señalado ya que la razón de ser de la tipificación de este delito no está en el cumplimiento de obligaciones supranacionales y, por otro lado, la justificación que el legislador español plasma en la Exposición de Motivos de 2010 es, a todas luces, insuficiente para conocer el ámbito de aplicación de este tipo delictivo. Señala la norma, únicamente, que "se ha considerado conveniente tipificar penalmente las conductas más graves de corrupción en el deporte. En este sentido se castigan todos aquellos sobornos llevados a cabo tanto por los miembros y colaboradores de entidades deportivas como por los deportistas, árbitros o jueces, 
encaminados a predeterminar o alterar de manera deliberada y fraudulenta el resultado de una prueba, encuentro o competición deportiva, siempre que estas tengan carácter profesional".

\subsubsection{Algunos comentarios sobre el tipo}

Como se comentará a continuación, dadas estas premisas, una de las cuestiones más controvertidas de este tipo penal es precisamente el bien jurídico que se trata de proteger, existiendo en la doctrina un intenso debate al respecto. Desafortunadamente, ante la ausencia, todavía hoy, de pronunciamientos firmes por parte de Jueces y Tribunales, a pesar de los años de vigencia del ilícito, esta cuestión sigue sin ser pacífica. Antes de enfocar esta cuestión fundamental, deben apuntarse algunos elementos de interés.

La primera apreciación que debe hacerse es que el delito de corrupción deportiva en España se configura como una suerte de especie dentro del género "corrupción privada" (Gili Pascual, 2012, p. 15). Cortés Bechiarelli entiende, en otras palabras, que para el legislador la corrupción deportiva es concebida, desde una perspectiva auténtica y sistemática, como una manifestación más, pero distinta, de los delitos de corrupción privada genérica (Cortés Bechiarelli, 2012, p. 29). Más tarde apuntaré que esto tiene, necesariamente, alguna repercusión en sede de bien jurídico.

El segundo elemento relevante es la propia configuración de la conducta típica, que se determina por envío a los apartados anteriores del propio artículo 286bis (Blanco Cordero, 2010, p. 1115), lo que para algunos autores supone encontrarnos ante una suerte de norma penal en blanco (Santana \& Gómez Martín, 2011, p. 636), si bien a juicio de quien esto escribe, esta consideración plantea dudas pues es generalmente aceptado que la técnica legislativa de la norma penal en blanco supone la existencia de una norma penal abierta que configura su supuesto de hecho, total o parcialmente, por remisión a disposiciones de otras ramas del ordenamiento jurídico (Muñoz Conde \& García Arán, 2015, p. 40), siendo más conveniente, quizás, hablar de que se trata de una norma de remisión.

\subsubsection{La cuestión del bien jurídico protegido}

Dada la relevancia absoluta del bien jurídico en un Derecho penal democrático, el debate respecto del delito de corrupción en el deporte se hace más necesario dado que, como se ha visto, la inclusión de este tipo en el Código respondió, únicamente, a la voluntad del legislador español.

En este sentido, pues, Muñoz Ruiz advierte que, en el delito de corrupción en el deporte, "no queda muy claro qué es lo que se está protegiendo ni tampoco la doctrina se pone de acuerdo" (Muñoz Ruiz, 2010, p. 39). Una primera corriente, niega que tras la incriminación del fraude deportivo en España exista un interés digno de tutela penal. En esos términos se expresa De Vicente Martínez, cuando asegura que "en el ámbito de la corrupción deportiva falta un bien jurídico que dé cobertura a la regulación propuesta" (Vicente Martínez, 2010, p. 555). En la misma línea se pronuncia Caruso Fontán quien sostiene que "el deporte es una actividad privada donde no es posible hallar un bien jurídico a proteger más allá del patrimonio. Desde nuestro punto de vista, no existe ningún bien jurídico de 'lealtad deportiva' que pueda merecer protección penal” (Caruso Fontán, 2009, p. 172).

De entre la doctrina que sí reconoce algún bien jurídico tras este delito, la amalgama de posibles intereses tutelados es amplia. En primer lugar, un grupo de autores - de los que son exponente máximo Morillas Cueva, García Caba y Benítez Ortúzar -, entienden que el interés penalmente valioso que justifica la criminalización del fraude deportivo es lo que dan en llamar la "integridad deportiva". Mientras que García Caba entiende este bien jurídico como sinónimo del valor "lealtad deportiva", para Morillas Cueva se trataría de un "bien de naturaleza colectiva que engloba fundamentalmente aquellas actividades que adulteren y conculquen los valores esenciales inmanentes al concepto de deporte" (Morillas Cueva, 2009, p. 69) y, finalmente, según Benítez Ortúzar es aglutinador de una serie de valores consustanciales al deporte: lealtad deportiva o fair 
play, salud pública, salud individual de los deportistas y los intereses económicos inherentes a la práctica de determinados eventos deportivos. (García Caba, 2009b, p. 86).

El desarrollo llevado a cabo por Benítez Ortúzar tiene tras de sí el reconocimiento de que el fair play o la pureza en las relaciones deportivas puede ser un valor digno de reconocimiento social, pero, en todo caso, no goza de entidad lesiva suficiente para ser un bien jurídico-penal idóneo de proteger (Benítez Ortúzar, 2011, p. 116). Pues bien: esta opinión es compartida por Cortés Bechiarelli, autor que, sin embargo, tampoco concuerda con la consideración de bien jurídico de la "integridad deportiva" (Cortés Bechiarelli, 2012, p. 53; pp. 65-66). Podría decirse, entonces, que integra el grupo de autores que no encuentran un bien jurídico válido como sustento político-criminal de este delito.

Frente a estas consideraciones, otro sector doctrinal, con el cual me alineo, considera que la inclusión de la corrupción en el deporte como un subtipo de corrupción privada hace pensar que el legislador otorga un reproche penal a estas conductas debido a su relevancia económica, considerando el deporte, más allá de como una actividad física, como una actividad económica susceptible de atraer negocios de mayor o menor licitud (Torres Fernández, 2017, p. 293). Así, por tanto, la consideración de este ilícito como un delito socioeconómico limitaría el alcance del injusto a la distorsión de resultados deportivos que suponga una alteración significativa para el funcionamiento del mercado (Berdugo Gómez de la Torre/Cerina, 2012, p. 10), tutelándose las expectativas económicas de todos los intervinientes en el fenómeno deportivo.

\subsection{La reforma de marzo de 2015}

Como se ha indicado, el tipo del párrafo cuarto del artículo 286 bis se modificó de modo relevante tras la entrada en vigor de la Ley Orgánica 1/2015, a pesar de que no existía pronunciamiento judicial firme que revelara defectos de técnica legislativa o de objeto específico de protección. Así, la nueva redacción reza como sigue:

Artículo 286 bis.

4. Lo dispuesto en este artículo será aplicable, en sus respectivos casos, a los directivos, administradores, empleados o colaboradores de una entidad deportiva, cualquiera que sea la forma jurídica de ésta, así como a los deportistas, árbitros o jueces, respecto de aquellas conductas que tengan por finalidad predeterminar o alterar de manera deliberada y fraudulenta el resultado de una prueba, encuentro o competición deportiva de especial relevancia económica o deportiva.

A estos efectos, se considerará competición deportiva de especial relevancia económica, aquélla en la que la mayor parte de los participantes en la misma perciban cualquier tipo de retribución, compensación o ingreso económico por su participación en la actividad; y competición deportiva de especial relevancia deportiva, la que sea calificada en el calendario deportivo anual aprobado por la federación deportiva correspondiente como competición oficial de la máxima categoría de la modalidad, especialidad, o disciplina de que se trate.

Artículo 286 quater.

1. Si los hechos a que se refieren los artículos de esta Sección resultaran de especial gravedad, se impondrá la pena en su mitad superior, pudiéndose llegar hasta la superior en grado.

Los hechos se considerarán, en todo caso, de especial gravedad cuando: a) el beneficio o ventaja tenga un valor especialmente elevado, b) la acción del autor no sea meramente ocasional, c) se trate de hechos cometidos en el seno de una organización o grupo criminal, o d) el objeto del negocio versara sobre bienes o servicios humanitarios o cualesquiera otros de primera necesidad. En el caso del apartado 4 del artículo 286 bis, los hechos se considerarán también de especial gravedad cuando: a) tengan como finalidad influir en el desarrollo de juegos de azar o apuestas; o b) sean cometidos en una competición deportiva oficial de ámbito estatal calificada como profesional o en una competición deportiva internacional. 
Del texto legal actualmente vigente, son dos las consideraciones más importantes que deben hacerse: en primer lugar, la sustitución del ámbito específico de protección de la prueba, encuentro o competición deportiva profesional a aquella que ostente una especial relevancia económica o deportiva, así como la definición auténtica de esta expresión contenida en el propio precepto. Se aplicará el delito en aquellos eventos deportivos en los que la mayor parte de los participantes en la misma perciban cualquier tipo de retribución, compensación o ingreso económico por su participación en la actividad, o bien, aquellos que sean calificados en el calendario deportivo anual aprobado por la federación deportiva correspondiente como competición oficial de la máxima categoría.

En segundo término, la previsión, ex novo, de unos supuestos agravados en el artículo 286 quater. De un lado, se impondrá la pena en su mitad superior, pudiéndose llegar a la superior en grado, bien cuando concurra alguna de las cuatro circunstancias aplicables a todas las figuras de corrupción en los negocios - contenidas en las letras a) a d) del segundo inciso del artículo 286 quater. 1 CP -, bien cuando la predeterminación o alteración tenga por objeto influir en juegos de azar o apuestas o cuando se trate de una competición oficial de ámbito estatal o competición deportiva internacional. Aunque excede del objetivo de este trabajo, quisiera apuntar que, dada la redacción vigente, existirán problemas de interpretación y de deslinde entre el tipo básico de competición de especial relevancia deportiva y el agravado de competición oficial de ámbito estatal (Magro Servet, 2015, p. 7).

\subsubsection{El bien jurídico protegido tras la reforma}

Si bien la Exposición de Motivos de la L.O. 1/2015 nada dice en torno a la modificación del ilícito de corrupción deportiva, coincido con aquellas tesis doctrinales que sugieren que la ubicación de esta figura delictiva entre los delitos de corrupción en los negocios - destinados a penar todos los casos en los que, mediante el pago de sobornos, en beneficio propio o de tercero, se obtienen posiciones de ventaja en las relaciones económicas, según recoge el Preámbulo de la citada norma orgánica -, así como la modificación de la redacción típica de los delitos de corrupción entre particulares - a los que se remite el tipo específico en el deporte, con la eliminación del elemento típico del "incumplimiento de obligaciones"- y la propia configuración típica vigente del fraude deportivo - con la modificación del ámbito típico a las pruebas, encuentros y competiciones de especial relevancia económica y la tutela reforzada a los apostadores del artículo 286 quater CP -, deben llevarnos necesariamente a la conclusión de que el bien jurídico objeto de protección se cifra en los intereses económicos derivados del "hecho deportivo".

\section{El delito de fraude deportivo en Portugal}

Como se indicaba anteriormente, la tipificación de la corrupción en el deporte en el ordenamiento penal portugués se llevó a término tras la repercusión del conocido como caso 'Silbato Dorado' en el año 2004. La concreta literalidad se recoge en la Lei $n^{\circ}$ 50/2007, de 31 de agosto, sobre régimen de responsabilidad penal por comportamientos antideportivos; norma penal especial que ha sido modificada en dos ocasiones, la última de ellas en 2017, con reformas de importante calado. Así, la regulación vigente en el ordenamiento penal luso es la siguiente:

Artigo $8^{\circ}$. Corrupção pasdiva.

O agente desportivo que, por si, ou por interposta pessoa, com o seu consentimento ou ratificação, solicitar ou aceitar, para si ou para terceiro, sem que lhe seja devida, vantagem patrimonial ou não patrimonial, ou a sua promessa, para um qualquer ato ou omissão destinados a alterar ou falsear o resultado de uma competição desportiva, ainda que anteriores àquela solicitação ou aceitação, é punido com pena de prisão de 1 a 8 anos.

Artigo $9^{\circ}$. Corrupção ativa.

1 - Quem, por si ou por interposta pessoa, com o seu consentimento ou ratificação, der ou prometer a 
agente desportivo, ou a terceiro com conhecimento daquele, vantagem patrimonial ou não patrimonial, que the não seja devida, com o fim indicado no artigo anterior, é punido com pena de prisão de 1 a 5 anos. 2 - A tentativa é punível.

\subsection{El bien jurídico protegido}

Se ha mencionado anteriormente que el delito de corrupción deportiva se introduce en el ordenamiento penal portugués a través de la Lei $n^{\circ}$ 50/2007. A diferencia de lo que ocurre con el tipo penal español, en el caso portugués el bien jurídico se encuentra determinado expresamente en la norma legal, concretamente en el sumario de esta, cuando reconoce que los comportamientos que serán penalmente relevantes serán aquellos susceptibles de afectar a la verdad, la lealtad y la corrección de la competición y de su resultado en la actividad deportiva.

Así las cosas, se averigua de modo claro que el legislador portugués ha tenido claro, desde un principio, cuál es el interés digno de tutela penal - ya en el Decreto-Lei $n^{\circ}$ 390/1991, precedente de esta norma, se atisbaba la protección de este valor -, acercando el objeto de protección a la noción de fair play expresada en párrafos previos.

\subsection{Otras cuestiones de interés}

Como dato interesante, ha de señalarse que esta ley penal especial propia recoge no sólo los delitos de corrupción deportiva antecedente activa y pasiva - como sucede, por ejemplo, en el Código penal español -, sino que, tras la reforma de esta ley en 2017, se incorpora también en el artículo 8 una modalidad de corrupción deportiva pasiva subsiguiente, en la que el acto de alteración del resultado es anterior a la solicitud o aceptación de la dádiva. De otro lado, además de los delitos de corrupción deportiva, la norma portuguesa recoge también las conductas de tráfico de influencias en el deporte (artículo 10).

Merece comentario también, a mi parecer, algo que, desde mi punto de vista, supone una ventaja respecto de la legislación penal española. Está extendido entender que utilizar una ley penal especial supone un riesgo de segmentación y fragmentación de la normativa penal, pero como punto positivo, permite definir de un modo más preciso cuestiones como los sujetos o la conducta, aspectos en los que la norma española es deficiente al configurarse, como se ha dicho, como una norma de remisión.

\section{Tipos de corrupción y fraude deportivos en Brasil}

La Lei $n^{\circ}$ 12.299/2010 incluyó algunos tipos penales en el Estatuto de Defensa del Espectador (Schmitt de Bem, 2015, p. 310). Concretamente, a través de los artículos 41-C, D y E de la norma. El tipo penal sigue, según refiere algún autor, el modelo de tutela competencial y se orienta según la estructura de los delitos de corrupción pública previstos en el Código penal brasileño. Así, el bien jurídico se configura como de titularidad colectiva, privilegiando la posición del espectador que, en este contexto, no es un simple aficionado, sino que adquiere la posición de consumidor (Schmitt de Bem, 2015, pp. 318-319). Dadas estas coordenadas parece obvio que el núcleo de lesividad se acerca a la concurrencia leal en el ámbito deportivo, significando la salvaguarda de los intereses económicos vinculados al deporte.

La normativa penal brasileña sobre fraude deportivo fue reformada levemente, además, a través de la Lei $n^{\circ}$ 13.155/2015 para resultar la legalidad vigente la que sigue:

Art. 41-C. Solicitar ou aceitar, para si ou para outrem, vantagem ou promessa de vantagem patrimonial ou não patrimonial para qualquer ato ou omissão destinado a alterar ou falsear o resultado de competição esportiva ou evento a ela associado:

Pena - reclusão de 2 (dois) a 6 (seis) anos e multa. 
Art. 41-D. Dar ou prometer vantagem patrimonial ou não patrimonial com o fim de alterar ou falsear o resultado de uma competição desportiva ou evento a ela associado:

Pena - reclusão de 2 (dois) a 6 (seis) anos e multa.

Art. 41-E. Fraudar, por qualquer meio, ou contribuir para que se fraude, de qualquer forma, o resultado de competição esportiva ou evento a ela associado:

Pena - reclusão de 2 (dois) a 6 (seis) anos e multa.

Como elemento destacable, ha de señalarse que el ordenamiento penal brasileño castiga tanto delitos de corrupción activa (art. 41-D) como pasiva (art. 41-C) - entendidos casi como sinalagma entre acción corrupta y contraprestación - en el deporte, así como cualquier otro fraude con objeto de alterar el resultado de la competición deportiva (art. 41-E).

Cada una de las conductas se penaliza en preceptos penales independientes, por lo que las modalidades de corrupción deportiva son autónomas entre sí. Llama la atención, no obstante, la ausencia de mención expresa del agente deportivo como sujeto de la corrupción pasiva, si bien parece claro que debe tratarse de un sujeto con capacidad para adulterar el resultado del evento deportivo (Schmitt de Bem, 2015, p. 319).

\subsection{Otras cuestiones de interés}

En añadidura a las conductas de corrupción, en sentido estricto, el Estatuto del Espectador brasileño recoge algunas otras disposiciones que merecen ser reseñadas en este momento.

El artículo 41-F recoge una modalidad de fraude consistente en la venta de entradas u otros pases para un evento deportivo a un precio superior al reflejado en el billete o documento - conducta castigada con pena de prisión de uno a dos años y multa -. Por su parte, el artículo 41-G otorga reproche penal a proporcionar, desviar o facilitar la distribución de entradas para la venta por precio superior al reflejado en el billete conducta castigada con pena de prisión de dos a cuatro años y multa -. Por último, el parágrafo único que da fin al Capítulo XI-A contiene una regla agravatoria de las penas, ampliándolas entre un tercio y la mitad en caso de que el agente deportivo sea servidor público, dirigente o empleado de una entidad deportiva, de una entidad responsable de la organización de la competición, o de una empresa contratada para el proceso de emisión, distribución y venta de entradas y el sujeto se valiese de tal condición para los fines previstos en el artículo 41.

\section{La corrupción deportiva en visión comparada}

El análisis dogmático de los delitos de corrupción deportiva en cada uno de los tres países estudiados en esta investigación no estaría completo si no lo aderezamos con unas observaciones en clave comparada donde relacionar los puntos de conexión y las diferencias entre las tipologías delictivas objeto de examen. Ello facilitará, además, la extracción de conclusiones relevantes en el último apartado de este trabajo. Antes de comenzar se previene al lector de que las aportaciones que se desarrollarán en este epígrafe tomarán en cuenta siempre la versión actualmente vigente de estos delitos en España, Portugal y Brasil.

El primer comentario debe venir referido, necesariamente, a los distintos bienes jurídicos que tratan de tutelarse en cada uno de los tres ordenamientos. A este respecto, la única regulación que explicita el interés digno de tutela es la portuguesa, que cifra el objeto de protección en la verdad, la lealtad y la corrección de la competición y de su resultado en la actividad deportiva. Por su parte, tanto en España como en Brasil el bien jurídico parece ir en la línea de salvaguarda de los intereses económicos derivados del espectáculo deportivo -concretándose en la concurrencia leal en el evento deportivo -, siendo que, en el caso español este bien jurídico se extrae como correlato al que justifica la tipificación de la corrupción privada y, en el 
brasileño, parece más fruto de las primeras voces doctrinales que se han pronunciado sobre el particular. Resulta relevante también profundizar en las modalidades delictivas tipificadas en cada uno de estos ordenamientos. Comparten los tres países el castigo penal de la llamada corrupción deportiva antecedente por adulteración de resultados, tanto en su vertiente activa como pasiva. Esto significa que será penalmente reprochable la conducta consistente en modificar fraudulentamente el resultado de un acontecimiento deportivo - definido en España como "prueba, encuentro o competición deportiva", en Portugal como "competición deportiva" y en Brasil como "competición deportiva o evento asociado a ella" - que sea posterior -consecuencia - al ofrecimiento o entrega, o a la solicitud o aceptación previa de un soborno definido en España como "ventaja no justificada de cualquier naturaleza", por remisión a la literalidad típica de la corrupción privada, y en Portugal y Brasil como "ventaja patrimonial o no patrimonial" -. Y, como decíamos, se castiga dicha corrupción deportiva antecedente parta la iniciativa delictiva bien del particular que corrompe - configurándose la corrupción activa como delito común en los tres ordenamientos - o bien del sujeto vinculado al evento deportivo que es corrompido - entendiéndose la modalidad de corrupción pasiva como delito especial; viéndose ello más claro en las legislaciones española y portuguesa.

Más allá de estas líneas legislativas conexas, los ordenamientos portugués y brasileño presentan algunas particularidades que no están presentes en el Código penal español. Por un lado, en Portugal, desde 2017, se penaliza también la corrupción deportiva subsiguiente, es decir, aquella cuyo soborno se produce con posterioridad al acto de adulteración corrupta del resultado deportivo. Como se ha defendido en un momento anterior, en mi opinión esta modalidad es solo predicable de la corrupción pasiva, pues solo está expresamente prevista en el artículo 8, si bien la redacción dada al artículo 9 podría dejar abierta la puerta a entender que esa nueva corrupción subsiguiente pudiera ser típica también en el supuesto de la corrupción deportiva activa. En todo caso, la ausencia de pronunciamientos doctrinales y jurisprudenciales en Portugal sobre este particular, al momento de elaborar esta investigación, dejan este aspecto abierto para futuros debates. También resulta particular, en la regulación portuguesa, la criminalización de la tentativa en la corrupción deportiva activa (a tenor de lo dispuesto en el artículo 9.2 antes referido); extremo que no comparten las normas española ni brasileña.

Desde el lado brasileño, llama la atención, diferentemente a los otros dos ordenamientos analizados que, además de tipificar la corrupción deportiva por adulteración de resultados, el artículo 41-E del Estatuto de Defensa del Espectador recoge una modalidad de cierre que castiga el fraude de la competición por cualquier (otro) medio que no implique, necesariamente, la modificación del resultado.

Como última apreciación, conviene profundizar en la modalidad de corrupción deportiva pasiva (recuérdese, aquella en la que un sujeto vinculado al evento deportivo solicita, acepta o recibe un soborno a cambio de llevar a cabo una actuación u omisión corrupta que adultere el resultado de la competición). Se ha indicado anteriormente que tanto en el ordenamiento penal español como en el portugués se configura, expresamente, como delito especial que solo puede ser cometido por aquellos individuos que poseen una determinada relación o posición jurídica respecto del evento deportivo. En el caso brasileño, la redacción abierta del artículo 41-C del Estatuto de Defensa del Espectador no cierra la opción unívoca de entender la corrupción deportiva pasiva como delito especial; sin embargo, argumentos de política criminal aconsejan decantarse por esta interpretación.

Así las cosas, ahondando en esta cuestión, la Lei $n^{\circ}$ 50/2007 define a estos sujetos de forma genérica como "agente deportivo", ofreciendo un concepto auténtico de tal categoría en el artículo 2 f) de la citada norma. A efectos de los delitos de corrupción deportiva se entiende por "agente deportivo" a todas las personas individuales o colectivas referidas en las líneas anteriores (dirigentes, técnicos, árbitros, empresarios o personas colectivas deportivos), así como a las que, incluso provisional o temporalmente, mediante remuneración o a título gratuito, voluntaria u obligatoriamente, a título individual o integradas en un conjunto, participen en una competición deportiva o sean llamadas a desempeñar o participar en el desempeño de la competición deportiva. Por su parte, el apartado $4^{\circ}$ del artículo 286 bis del Código penal español relaciona, 
en un sistema de numerus clausus, los sujetos que pueden ostentar la condición de sujeto activo de esta modalidad delictiva, incorporando a los directivos, administradores, empleados o colaboradores de una entidad deportiva, cualquiera que sea la forma jurídica de esta, así como a los deportistas, árbitros o jueces.

\section{Conclusiones}

El objetivo fundamental de este trabajo es realizar un sucinto análisis de los tipos de corrupción deportiva; delitos característicos del llamado moderno Derecho penal económico, tomando como referencia los ordenamientos jurídicos español, portugués y brasileño, por constituir regulaciones paradigmáticas en los respectivos ámbitos normativos regionales. Para el desarrollo de esta investigación, se ha seguido una metodología analítica comparada, siendo apoyada ésta por aportaciones doctrinales autorizadas, en ausencia de producción jurisprudencial relevante, de cada uno de los tres países referidos.

Los fenómenos de corrupción se han extendido en los últimos años, llegando a hablarse, en algunos países, de manifestaciones inequívocamente sistémicas. Ello ha aumentado la preocupación nacional e internacional por estos hechos y ha generado la necesidad de intervención jurídica, particularmente del Derecho penal, en aras a prevenir, regular y sancionar los comportamientos más graves.

Si bien tradicionalmente se ha vinculado la intervención penal ante la corrupción a las conductas acaecidas en el ámbito público, las nuevas realidades derivadas de la globalización y los efectos perversos que los comportamientos corruptos generan en instituciones de todo orden han hecho necesaria la criminalización de hechos delictivos corruptos en el sector privado y, como se ha expuesto en este estudio, en el deporte; consecuencia ello de la innegable trascendencia social y económica de los eventos deportivos, que han hecho surgir, en los últimos años, un verdadero mundo de los negocios en el deporte.

De los tres ordenamientos penales estudiados, se concluye que los legisladores han seleccionado, primordialmente, castigar penalmente la corrupción deportiva consistente en adulterar fraudulentamente los resultados, por ser estos los mayores indicadores de la imprevisibilidad de la competición, aspecto fundamental en todo acontecimiento deportivo. No obstante, el ejemplo brasileño nos muestra que la tutela penal ante la corrupción deportiva puede justificarse más allá de la sola tutela de la imprevisibilidad de los resultados.

Del trabajo realizado se extrae la necesidad de profundizar en el estudio, análisis y reflexión político-criminal acerca de la eficacia e idoneidad de estos delitos, por cuanto en ninguno de los tres países elegidos existe una importante aplicación jurisprudencial de los distintos tipos penales. Tampoco la doctrina ha fijado especial atención en estas normas penales, siendo, quizás, España la excepción; si bien la producción teórica es eminentemente reciente, por lo que debe ahondarse en la necesidad de tipificar estos delitos y en su adecuación a los más básicos principios limitadores del ius puniendi en un Estado democrático y de Derecho para evitar, en lo posible, que criminalizaciones como la aquí comparada se conviertan en un ejemplo más de Derecho penal simbólico. 


\section{NOTAS}

1 Acerca de la función social del deporte se pronunció el Informe de la Comisión al Consejo Europeo con la perspectiva de la salvaguardia de las estructuras deportivas actuales y del mantenimiento de la función social del deporte en el marco comunitario, conocido como Informe de Helsinki sobre el deporte, hecho en Bruselas, el 10 de diciembre de 1999. A este respecto, se indica que: "esta función social, de interés general, del deporte se ha visto afectada desde hace varios años por la aparición de nuevos fenómenos de diferentes características, que en ocasiones menoscaban la ética y los principios de organización del deporte: la violencia en los estadios, la expansión de las prácticas de dopaje o la búsqueda de beneficios financieros rápidos en detrimento de una evolución más equilibrada del deporte". Informe disponible en Internet. Recuperado de [http://eur-lex.europa.eu/legal-content/ES/TXT/PDF /?uri=CELEX:51999DC0644\&from=EN]. Consultado [902-2019].

2 STS 15186/1988, de 23 de marzo, Sala de lo Contencioso-Administrativo.

\section{REFERENCIAS BIBLIOGRÁFICAS}

Benítez Ortúzar, I. F. (2011). El delito de "fraudes deportivos". Aspectos criminológicos, político-criminales y dogmáticos del artículo 286bis.4 del Código Penal. Madrid: Dykinson.

Berdugo Gómez de la Torre, I. \& Cerina, G. M. (2012). Algunos problemas del nuevo delito corrupción en el deporte. Revista General de Derecho Penal (18). Madrid: lustel, 1-19.

Blanco Cordero, I. (2010). Sección 4a . De la corrupción entre particulares. En M. Gómez Tomillo (Dir.). Comentarios al Código Penal. Valladolid: Lex Nova.

Caruso Fontán, M. V. (2009). El concepto de corrupción. Su evolución hacia un nuevo delito de fraude en el deporte como forma de corrupción en el sector privado. Revista Foro. Nueva época (9), 145-172.

Convención de Naciones Unidas contra la Corrupción. Mérida (México), 11 de diciembre de 2003.

Cortés Bechiarelli, E. (2012). El delito de corrupción deportiva. Valencia: Tirant lo Blanch.

Eser, A. (1990). Lesiones deportivas y Derecho penal. En especial, la responsabilidad del futbolista desde una perspectiva alemana. Revista Jurídica Española La Ley (Diario La Ley) (t. 2). Madrid: La Ley, 1130-1141.

Flórez, M. (2008). Prólogo. En N. Rodríguez García \& E. A. Fabián Caparrós (Coords.). Corrupción y delincuencia económica. Bogotá: Universidad de Santo Tomás-Grupo Editorial Ibáñez.

García Caba, M. M. (2009). Breve comentario a la lei portuguesa 50/2007, de 31 de agosto, por la que se establece un nuevo régimen de responsabilidad penal por comportamientos susceptibles de afectar a la verdad, la lealtad y la corrección de la competición deportiva y sus resultados y su posible extrapolación al ordenamiento español. Revista Aranzadi de Derecho de Deporte y entretenimiento (25), Navarra: Aranzadi, 319335.

García Caba, M. M. (2009b). ¿Hacia una (necesaria) presencia del Derecho penal para garantizar la integridad de la competición profesional? A propósito del Proyecto de Ley de la LFP contra el fraude en el deporte. En M. Cardenal Carro, M. M. García Caba \& E. A. García Silvero (Coords.): ¿Es necesaria la represión penal para evitar los fraudes en el deporte profesional? (pp. 73-104). Murcia: Laborum.

Gili Pascual, A. (2012). La tipificación penal del fraude en competiciones deportivas. Problemas técnicos y aplicativos. Revista de Derecho Penal y Criminología. $3^{a}$. Época (8). Madrid: UNED, 13-70.

Informe de la Comisión al Consejo Europeo con la perspectiva de la salvaguardia de las estructuras deportivas actuales y del mantenimiento de la función 
social del deporte en el marco comunitario. Bruselas, 10 de diciembre de 1999. COM (1999) 644 final.

Magro Servet, V. (2015). La corrupción en el deporte en la reforma del Código Penal (nuevo artículo 286 bis.4). Diario La Ley (1537). Madrid: Wolters Kluwer, 3-8.

Morillas Cueva, L. (2009). El tratamiento jurídico del fraude en el deporte en el Derecho comparado. Las experiencias de Italia, Portugal y Alemania. En M. Cardenal Carro, M. M. García Caba \& E. A. García Silvero (Coords.): ¿Es necesaria la represión penal para evitar los fraudes en el deporte profesional? (pp. 39-69). Murcia: Laborum.

Muñoz Conde, F. \& García Arán, M. (2015). Derecho Penal. Parte General ( $9^{\mathrm{a}}$ ed., revisada y puesta al día conforme a las Leyes Orgánicas 1/2015 y 2/2015, de 30 de marzo). Valencia: Tirant lo Blanch.

Muñoz Ruiz, J. (2010). El nuevo delito de corrupción en el deporte. Revista Andaluza de Derecho del Deporte (9), 31-54.

Nieto Martín, A. (2002). La corrupción en el sector privado (reflexiones desde el ordenamiento español a la luz del Derecho comparado. Revista Penal (10), 55-69.

Organización de las Naciones Unidas (2003). Convención de las Naciones Unidas contra la Corrupción. Recuperado de [https://www.unodc.org/pdf/corruption/publications_ unodc_convention-s.pdf.] Consultado [9-02-2019].

Santana, D. \& Gómez Martín, V. (2011). Artículo 286 bis. En M. Corcoy Bidasolo \& S. Mir Puig (Dirs.). Comentarios al Código Penal. Reforma LO 5/2010 (pp. 634-637). Valencia: Tirant lo Blanch.

Schmitt de Bem, L. (2015). Responsabilidad penal en el deporte. Lisboa: Juruá

Torres Fernández, M. E. (2017). Reflexiones sobre la corrupción en las competiciones deportivas. A propósito del delito del artículo 286 bis 4 del Código Penal”. En F. Jiménez García \& J. Ropero Carrasco (Dirs.); A. Pastor Palomar (Coord.). Blanqueo de capitales y corrupción. Interacciones para su erradicación desde el Derecho Internacional y los sistemas nacionales (pp. 277-304). Navarra: Thomson Reuters-Aranzadi.

Vicente Martínez, R. de (2010). Derecho penal del deporte. Barcelona: Bosch. 